\title{
NEUROLOGICAL RARITY
}

\section{Maria Elena Farrugia*, Arthur Melms ${ }^{\dagger}$ and Angela Vincent ${ }^{\ddagger}$}

*Specialist Registrar in Neurology, Institute of Neurological Sciences, Glasgow; ${ }^{\text {Professor }}$ of Neurology, Department of Neurology, University of Tuebingen; :Professor of Neuroimmunology and Honorary Consultant in Imunology, Neurosciences Group, Weatherall Institute of Molecular Medicine and Department of Clinical Neurology, University of Oxford; Email: Angela.vincent@imm.ox.ac.uk

Practical Neurology, 2005, 5, 356-359

\section{INTRODUCTION}

Antibodies to the muscle acetylcholine receptor (AChR) are present in about $85 \%$ of patients with generalized myasthenia gravis, and $50 \%$ of patients with just ocular symptoms. However, up to $70 \%$ of the myasthenia patients without AChR antbodies, so called 'seronegative' myastheniagravis, haveantibodies to themusclespecific tyrosinekinase(MuSK).
MuSK is another protein at the postsynaptic membrane of the neuromuscular junction, and plays a role in agrin-induced AChR clustering (H och \& al. 2001). These patients may be difficult to recognize, and difficult to treat effectively. Here we describe four AChR antibody-negative/MuSK antibody-positive patients as examples.

Table 1 Features of four patients with MuSK-myasthenia gravis, and comparison with AChR positive myasthenia gravis

\begin{tabular}{|c|c|c|c|c|c|c|}
\hline CASE & SEX & $\begin{array}{l}\text { AGE AT } \\
\text { ONSET }\end{array}$ & PRESENTING FEATURES & DIAGNOSIS & TREATMENTS REQUIRED & OUTCOME \\
\hline 1 & $\mathrm{~F}$ & 30 & $\begin{array}{l}\text { Diplopia, dysarthria, } \\
\text { dysphagia }\end{array}$ & EMG positive & $\begin{array}{l}\text { Immunoabsorption, steroids, } \\
\text { azathioprine, cyclophosphamide, } \\
\text { mycophenolate, rituximax (Figure 1) }\end{array}$ & $\begin{array}{l}\text { In remission on } \\
\text { pyridostigmine and } \\
\text { cyclosporin (reduced dose) }\end{array}$ \\
\hline 2 & $\mathrm{~F}$ & 3 & Facial, ocular, bulbar & EMG positive & $\begin{array}{l}\text { Plasma exchange, steroids, } \\
\text { azathioprine, cyclosporin }\end{array}$ & $\begin{array}{l}\text { Persistent facial and } \\
\text { tongue wasting, atrophy } \\
\text { and fatty replacement on MRI. }\end{array}$ \\
\hline 3 & $\mathrm{~F}$ & 57 & $\begin{array}{l}\text { Diplopia, dysphagia, } \\
\text { no fatigue, flat affect }\end{array}$ & EMG negative & $\begin{array}{l}\text { Steroids not tolerated, } \\
\text { pyridostigmine only }\end{array}$ & $\begin{array}{l}\text { Improved bulbar and } \\
\text { respiratory symptoms }\end{array}$ \\
\hline 4 & $\mathrm{~F}$ & 77 & $\begin{array}{l}\text { Dysphagia, generalized } \\
\text { and ocular, neck and } \\
\text { respiratory weakness }\end{array}$ & EMG positive & Azathioprine not tolerated, steroids & $\begin{array}{l}\text { Improved bulbar and } \\
\text { respiratory symptoms }\end{array}$ \\
\hline \multicolumn{3}{|c|}{$\begin{array}{l}\text { Typical AChR } \\
\text { antibody-positive }\end{array}$} & $\begin{array}{l}\text { May be ocular, limb, } \\
\text { respiratory and/or } \\
\text { bulbar }\end{array}$ & EMG positive & $\begin{array}{l}\text { Steroids and azathioprine often } \\
\text { suffice. Some patients \& } 40 \text { years } \\
\text { may benefit from thymectomy }\end{array}$ & $\begin{array}{l}\text { Usually improve or go } \\
\text { into remission. Few are } \\
\text { difficult to treat. } \\
\text { Muscle atrophy uncommon }\end{array}$ \\
\hline
\end{tabular}




\section{THE CASES (SEE TABLE 1)}

\section{Case 1}

This patient had an age at onset and clinical presentation typical of myasthenia gravis but was difficult to treat. She was a 30-year old woman who developed diplopia, dysphagiaand dysarthriaduring thethird trimester of her first pregnancy. EM G showed a defect of neuromuscular transmission and she improved transiently on pyridostigmine (180 mg/day). The pregnancy was terminated by Caesarean section after shedeveloped pre-eclampsia. The baby showed only mild transient signs of neonatal myasthenia. The patient was managed with intravenousimmunoglobulin for progressive oculopharyngeal myasthenia and started on conventional immunosuppression with prednisolone and azathioprine. However, she suffered a severe myasthenic crisis, which required two courses of immunoadsorption of IgG antibodies (on a Protein-A column) and six courses of intravenous cyclophosphamide to induce a remission. The remission was sustained for several months, and prednisolone was tapered. She developed a rash, attributed to azathioprine which was replaced by mycophenolate. However, shebegan to deteriorate and 17 months after onset, despite three further courses of cyclophosphamide, she had another crisis that was treated with immunoadsorption and increased steroids. Four weekly treatments were given with anti-CD20 (rituximab), and mycophenolate was replaced with cyclosporin to maintain the remission. The symptoms then stabilized quitequickly and prednisolonewas slowly
Figure 1 The clinical course and treatments required in case 1 illustrate a particularly difficult case of MuSK-myasthenia gravis in a 30-year-old woman. After treatments with IVIg (not shown), cyclophosphamide, azathioprine, steroids and mycophenolate, she eventually went into a stable remission following treatment with anti-CD20 (rituximab) and cyclosporin, despite discontinuation of prednisolone. The MuSK antibodies, retested using $0.025 \mu \mathrm{L}$ of each stored serum, generally correlated well with score activities of daily living (Wolfe et al. 1999). Unfortunately there was no sample available at the peak of the second crisis. Cp, cyclophosphamide; M, mycophenolate.

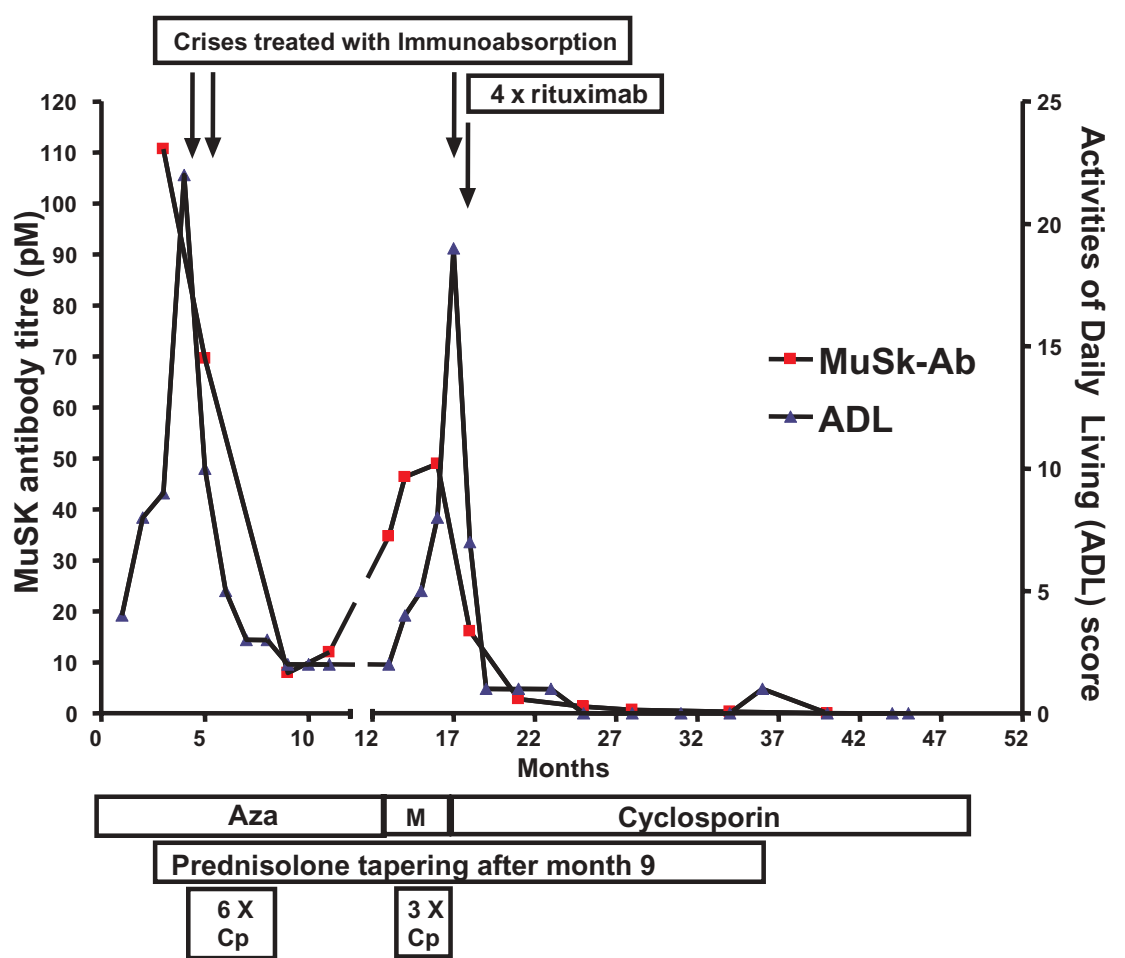


tapered again. Thepatient isstill on pyridostigmineand cyclosporin, has been in pharmacological remission for more than 2 years, and has now returned to work. Recently, the dose of cyclosporin was reduced because of raised blood pressure but no other adverse effects have occurred so far. Figure 1 shows her M USK antibodies and the Activities of Daily Living scoreover the period of study. MuSK antibody levels werevery high at onset and appeared to peak beforethe second crisis; they havenow declined to control values.

\section{Case 2}

This patient was unusual in presenting in early childhood and the development of persistent facial muscle and tongue atrophy. She presented with severefacial weakness at theage of 3 years, and subsequently developed a squint and nasal speech. Single fibre EM G when she was 14 years old was positive and to establish whether shehad an acquired form of myasthenia, sheunderwent plasma exchange, resulting in clear clinical improvement, and was started on corticosteroid treatment.Assoon asher condition stabilized, shewas weaned off steroids but at theage of 15 her symptoms relapsed with profound facial weakness and moderate axial and limb weakness. Steroids were reintroduced and she was started on azathioprine as asteroid-sparing agent, but shefailed to respond to thelatter so this was switched to cyclosporin to which, together with prednisolone, she responded well. Although her axial and limb problems have been, until recently, in remission, her severefacial weaknesspersists, and shehas marked nasal speech, although no dysphagia for solids or liquids. Strikingly, shehas severewasting of thetonguewith a triplefurrowed appearance, and M RI of thefacial and tonguemuscles hasconfirmed muscleatrophy, with abnormal high signal replacing most of theintrinsic tonguemusculature(Fig. 2).

\section{Case 3}

Thisillustrates thediagnostic difficulties in a less severely affected older patient, and the importance of the MuSK antibody assay.
She presented at age 57 complaining of diplopia, gait unsteadiness and dysphagia to solids with no regurgitation of fluids, extreme fatigue and loss of weight. She was noted to have a partial gaze pal sy to the left with limited upgaze, but therewas no ptosis and no features of fatigability. The tensilon test was negative, she did not respond significantly to oral acetylcholinesterase inhibitors, and single fibre EM G studies of both orbicularis oculi and extensor digitorum communis were normal. Thus, there was no objective evidence of myasthenia. Nevertheless, her MuSK antibody titres were clearly elevated. On steroids she developed a severe depressive illness, and she was then managed with pyridostigmine alone. Her symptoms have now resolved and she is off all treatment.

\section{Case 4}

This patient presented in later life. She suffered from increasing dysphagia and associated choking episodes at the age of 77 years. This progressed to generalized weakness with dyspnoea, bilateral ptosis, diplopia and moderate neck flexion weakness. She went into type II respiratory failure, at which time single fibre EM G demonstrated increased jitter in both orbicularis oculi and extensor digitorum communis. The patient was treated with a course of intravenous immunoglobulin and started on steroids and azathioprine. She required ventilatory support from which she was later successfully weaned. Unfortunately, she was intolerant of azathioprine because of hepatic enzyme derangement. Shewas discharged from hospital with her bulbar and respiratory symptoms having improved significantly and shecontinues to be managed with corticosteroids.

\section{DISCUSSION}

These four casesillustrate the main features of M uSK-myasthenia gravis. Typically patients are young females presenting between 10 and 40 years of age. H owever, about onein eight pa-
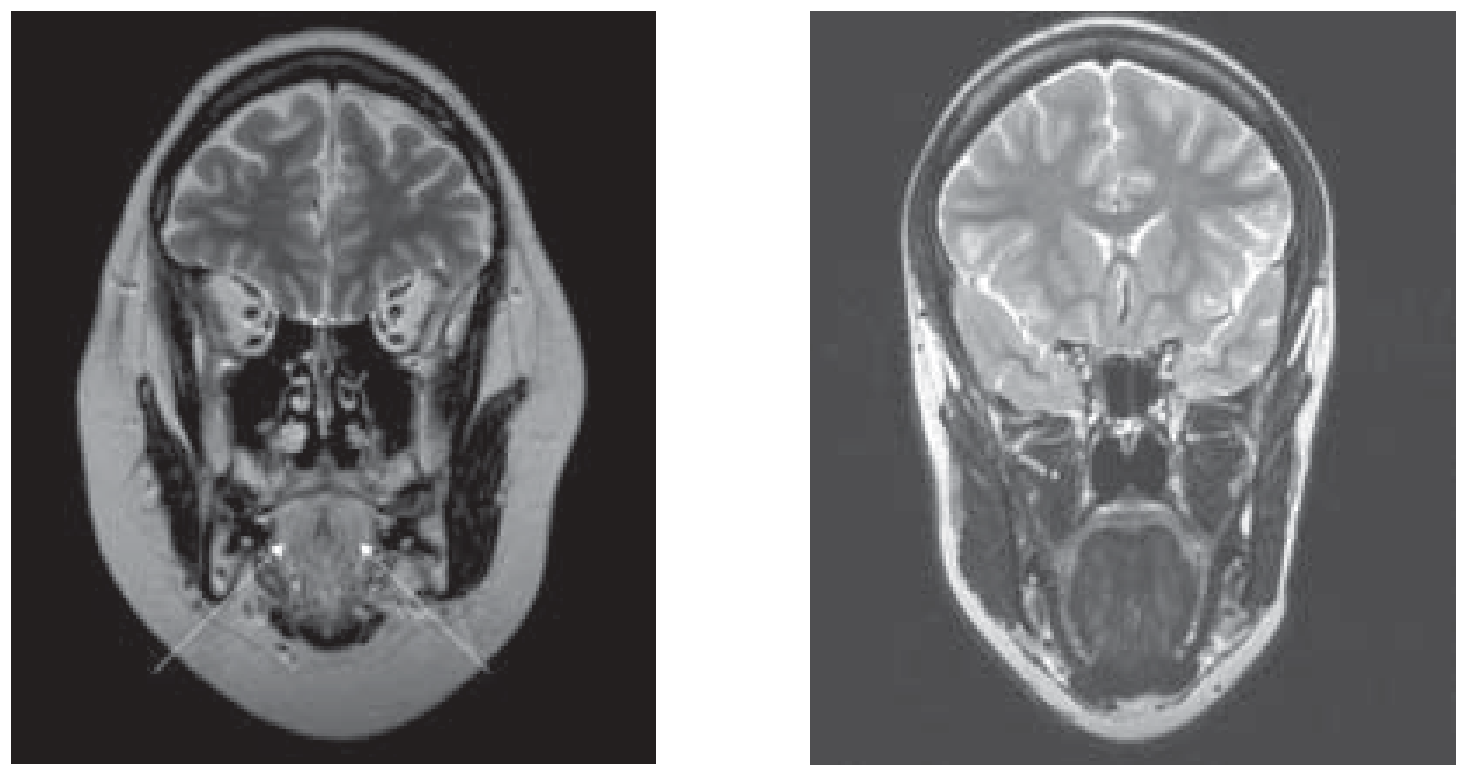

Figure 2 MR T2-weighted coronal sequences showing atrophy and fatty infiltration (high signal) in the tongue of case 2 (left), compared with normal appearance of healthy individual (right). 
tients are male (Vincent, unpublished data) and, with increased awareness of the disorder by neurologists, older cases are now being identified (cases 3,4 ). The patients often present with bulbar and ocular symptoms, but profound neck or respiratory weakness without other signs may occur (Sanders \& al. 2003; Zhou etal. 2004; M elmsA, unpublished). Limb and axial muscle involvement may be present in the acute phase of disease, but is seldom severe and usually responds readily to treatment. These patients can deteriorate rapidly (as in case 1 and 4), relatively frequently requiring ventilatory and nutritional support. Dysphagia and weight loss may at first suggest motor neuron disease (Case4), and somepatients may not complain of typical myasthenic fatigue (C ase 3 ).

It is important to note that, in contrast to AChR antibodypositive patients, the tensilon test may be only weakly positive. Also, singlefibreEM G studies on limb muscles may benormal at presentation, as in case 3 , and this has been noted frequently in patientsstudied following treatment (N emoto et al. 2005; Farrugiaet al. in preparation). M uscleatrophy, particularly of thefacial and bulbar muscles, seems to be a relatively common long-term consequence of the disease (Evoli \&t al. 2003; Sanders \& al. 2003; Fig. 2), perhaps because the condition can be relatively difficult to treat effectively, frequently responding poorly to steroids and azathioprine and sometimes requiring other immunosuppressiveagents (cases 1 and 2). It has also been noted that the patients may not respond well to acetylcholinesterase inhibitiors (Evoli etal. 2003; Sanders \& al. 2003); ambenonium chloride (mytelase) may betolerated better and can behel pful in some patients (A M elms, unpublished observations). N one of these four patients were treated with thymectomy, which is of doubtful benefit in M USK antibody-positive cases. In fact, two recent studies have shown that the histology of the M uSK-M G thymus is normal or near normal (Lauriola et al. 2005; Leite et al. 2005).

There are many unanswered questions about M uSK antibodyassociated myasthenia gravis. It is not clear what role MuSK plays at thematureneuromuscular junction, or even whether M USK an-

\section{CONCLUSIONS}

- MuSK-myasthenia gravis often presents with predominantly bulbar and ocular symptoms.

- Facial muscle atrophy is relatively common in long-standing M uSK - myasthenia gravis

- The age range at onset is wide although to date most patients are young adult females.

- Thereisno substantial thymuspathology

- Limb symptoms may remit with treatment whilefacial and bulbar weakness persists

- Neurophysiological studies usually show evidenceof transmission defect in facial muscles but may be normal in the limb muscles

- Response to plasma exchange is usually very good. Response to conventional treatments with prednisolone and azathioprine can bepoor, and additional immunosuppressive drugs may be required. tibodies cause disease. AChR numbers at theneuromuscular junction appear normal (Selcen \& al. 2004; Shiraishi \&al. 2005), and thereislittlecomplement deposition, probably becausetheM uSK antibodies are predominantly lgG4 which does not activate complement (McConvilleetal. 2004). Although originally reported in $70 \%$ of AChR antibody-negative patients, in a prevalence study performed in Oxford, the proportion of MuSK antibody-positive sera within AChR antibody-negative sera from different populations worldwide varies between 0 and $50 \%$, perhaps reflecting an environmental or genetic susceptibility factor (Vincent $\mathbb{e}$ al. in preparation). All these observations have led to some concerns about the relevance of MuSK antibodies. Nevertheless, they are very rare $(<1: 700)$ in community controls, and have not been found in any of $>200 \mathrm{AChR}$ antibody-positive patients studied in Oxford (Galati and Vincent unpublished results). M oreover, as in AchR antibody-positivecases, M uSK antibodiescorrelatewell with clinical severity (Fig. 1). Thus the antibody is highly specific for a form of myasthenia gravis that, although quite rare, has no other diagnostic serum marker and needs to beconsidered in the differential diagnosis of patients with unexplained weakness at all ages.

\section{ACKNOWLEDGEMENTS}

We are most grateful to Prof J N ewsom-D avis and Dr D HiltonJones for permission to study their patients and for their helpful comments on the manuscript. MEF was supported by the M yasthenia GravisAssociation/M uscular Dystrophy Campaign.

\section{REFERENCES}

Evoli A, Tonali PA, Padua L etal. (2003) Clinical correlates with anti-M uSK antibodies in generalized seronegative myasthenia gravis. Brain, 126, 2304-11.

Hoch W, McConville J, Helms S, Newsom-Davis J, M elms A \& Vincent A (2001) Auto-antibodies to the receptor tyrosine kinase MuSK in patients with myasthenia gravis without acetylcholinereceptor antibodies. Nature Medicine, 7, 365-8.

Lauriola L, Ranelletti F, M aggiano N et al. (2005) Thymus changes in antiMuSK-positive and - negative myasthenia gravis. Neurology, 64, 536-8.

LeiteM I, Ströbel P, Jones M \& al. (2005) Fewer thymic changesin M uSK-antibody positivethan in M USK-antibody negativeM G. Annalsof Neurology, 57, 444-8.

McConville J, ForrugiaM E, Beeson D et al. (2004) Detection and characterization of MuSK antibodies in seronegative myosthenia gravis. Annals of Neurology, 55, 580-4.

Nemoto Y, KuwabaraS, M isawaSetal. (2005) Patternsand severity of neuromuscular transmission failure in seronegative myasthenia gravis. Journal of Neurology, Neurosurgeryand Psychiatry, 76, 714-80.

SandersDB, El-Salem K, M asseyJ M , M cConvilleJ \& VincentA (2003) Clinical. aspects of M uSK antibody positive seronegative M G. Neurology, 60, 1978-80.

Selcen D, Fukuda T, Shen XM \& Engel AG (2004) Are MuSK antibodies the primary cause of myasthenic symptoms? Neurology, $\mathbf{2}$, 1945- 50.

Shiraishi H, M otomura M, Yoshimura T et al. (2005) Acetylcholine receptorsloss and postsynaptic damagein M uSK antibody-positivemyasthenia gravis. Annals of Neurology, 57, 289-93.

Wolfe GI , Herbelin L, NationsSP \&al. (1999) M yasthenia gravis activities of daily living profile. Neurology, 52 1487-9.

Zhou L, McConville J, Chaudhry V \&al. (2004) Clinical comparison of muscle-specific tyrosine kinase (M uSK) antibody-positive and - negative myasthenic patients. MusdeNerve, 30, 55-60. 